\title{
NUMERICAL SIMULATION OF ADVECTION-DISPERSION FOR MONITORING THERMAL PLUME RE-CIRCULATION IN A SHALLOW COASTAL ENVIRONMENT
}

\author{
PANIGRAHI, J.K. ${ }^{1} *-$ TRIPATHY, J.K. ${ }^{2}$ \\ ${ }^{1} L \& T-R A M B O L L$, India \\ ${ }^{2}$ Department of Remote Sensing \& GIS, North Orissa University, India \\ *Corresponding author \\ e-mail: Jeetendra@scientist.com
}

(Received $24^{\text {th }}$ April 2008; accepted $26^{\text {th }}$ August 2011)

\begin{abstract}
A numerical simulation study is carried out to assess the possible reject water circulation pattern around the Lekki coast, Nigeria. Critical decision like selection of suitable location for intake and outfall systems are decided based on the simulation results. The tide and wave induced flow pattern and the advection-dispersion of disposed thermal plume in the vicinity of the Lekki coast are established using hydrodynamic model (HD) and advection-dispersion (AD) model of Mike-21 suite of programs respectively. The modeling and simulation experiment is performed using the field measurements and the end results for critical scenarios are presented in this paper. The performance of the model is encouraging and it is a reliable tool for marine environmental monitoring.
\end{abstract}

Keywords: advection-dispersion, wastewater disposal, thermal plume

\section{Introduction}

The ocean has for all time been the ultimate sink for water-borne waste products coming from the industries. Marine disposal of wastewater is nothing more than a cosmetic name for the relocation of industrial effluent and the other associated wastes, whether it be treated or not and dumped into the sea by an outfall. The disposal is carried out by constructing a pipeline on the bed of the ocean with tunnel or risers and appropriate diffusers. The fundamental intent of wastewater disposal is to mix the effluent thoroughly with large volumes of ambient water. If the ocean is stratified then the diluted pollutant may reach an equilibrium level below the surface of the ocean and the ocean currents transport the effluent, it is further diluted by the surrounding turbulence (Rodi, 1980). However, in the shallow seas the diluted pollutant usually fail to find an intermediate equilibrium level and reaches the surface of the ocean with a density less than the salt water. In addition to the diffusion caused by ambient turbulence the effluent will spread because of its density difference. When wastewater enters the marine environment from the diffuser it is buoyant and tends to rise. This effluent, initially travelling horizontally after leaving the holes, or ports, gradually ascends on a more vertical path. Throughout its path, whether largely horizontal or vertical, the effluent mixes with ambient seawater. Generally marine outfall need to be located in minimum environmentally sensitive zone; therefore an open sea always preferred over estuary or bay. Depending on the natural topography of ocean permits, discharges usually made at a depth of 7 to $20 \mathrm{~m}$ or more (Wood et al., 1993). The depth is the important parameter because of two basic reasons, firstly where depth is more, significant density stratification exists in seawater column especially during summer months. In such cases mixed effluent plume won't rise to the ocean surface and will 
remain submerged at an intermediate location. Secondly, under unstratified ocean conditions, assuming density of discharged effluent to be less than the usual density of seawater, effluent would tend to rise to surface to form surfacing field. It is well known that the sea area microbiologically polluted by a given effluent discharge does not depend only on the effluent volume, but also, to a considerable extent, on the velocity and the direction of the sea currents affecting the discharge point; hence the point of discharge is of great importance for defining the area concerned. The coastal ecology is likely to get disturbed due to accumulation of waste in the estuarine region if the effluent is disposed near to the shore as sufficient dilution and dispersion is not available in such areas. Some times these discharged effluents may float on the surface, in case heavy or no circulation of waves and current the disposed effluent gets accumulated at the bottom of the seabed. Most reject waters has essentially the same density as fresh water and heated seawater used as cooling water is of less dense then seawater at normal temperature. So, it is buoyant and rises to the surface as turbulent jet. Here, a simulation study to assess heated water spreading is demonstrated as a real world problem.

The paper describes results of the numerical simulation for reject water re-circulation and advection-dispersion of thermal plumes coming from a polymer complex at Lekki free trade zone at Lagos state Nigeria. The total volume of seawater at the intake location and reject water at the outfall location is catered for $400,000 \mathrm{~m}^{3} / \mathrm{hr}$. The reject water is planned to be discharged through an open channel located in $2 \mathrm{~m}$ water depth on the seaward side of the western breakwater (Fig.1b), while the intake is located within the dredged harbor basin, along the eastern breakwater. Further selecting a correct location of intake structure with respect to discharge point carries great importance for efficiency of the system and for reduction of operational costs. In order to minimize environmental sensitivity and take appropriate engineering decision for confirming set of intake and outfall location, advection-dispersion modeling are performed coupling HD (hydrodynamic) and AD (Advection-Dispersion) model of Mike-21 (Abbott, 1985) suites of program. These models were developed by Danish Hydraulic Institute (DHI), Denmark and are being widely used worldwide for many coastal engineering applications.

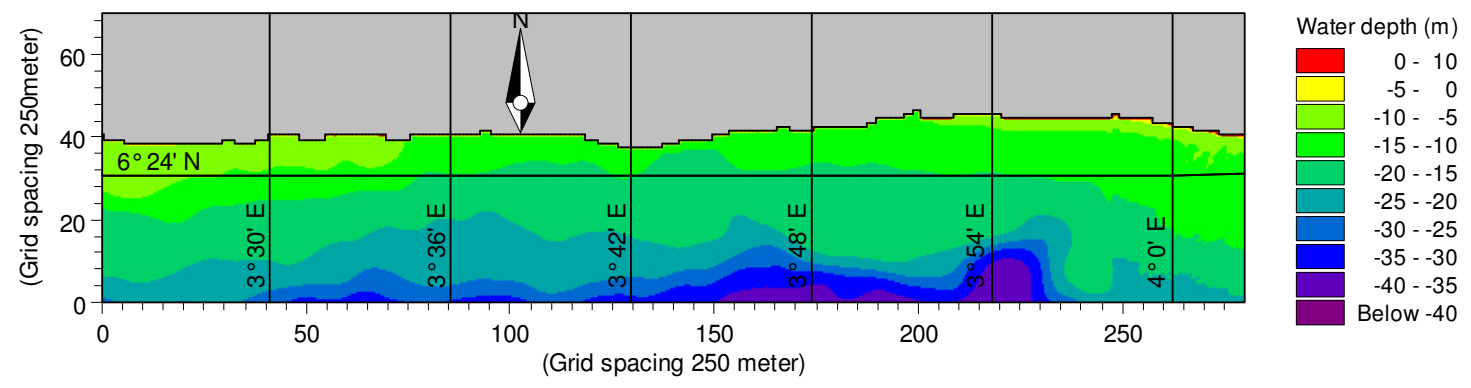

Figure 1a Coarse grid bathymetry

\section{Materials and methods}

In order to assess the circulation pattern of reject water hydrodynamic modeling and to determine movement of thermal plume, Advection-Dispersion modeling is implemented. The flow pattern and the associated current velocities in the surrounding 
waters primarily govern the movement of reject water from the outfall location. The currents in the coastal waters are generally governed by forcing due to tides and waves. Hence tide, wave and bathymetry data for the coast is collected by field measurements.

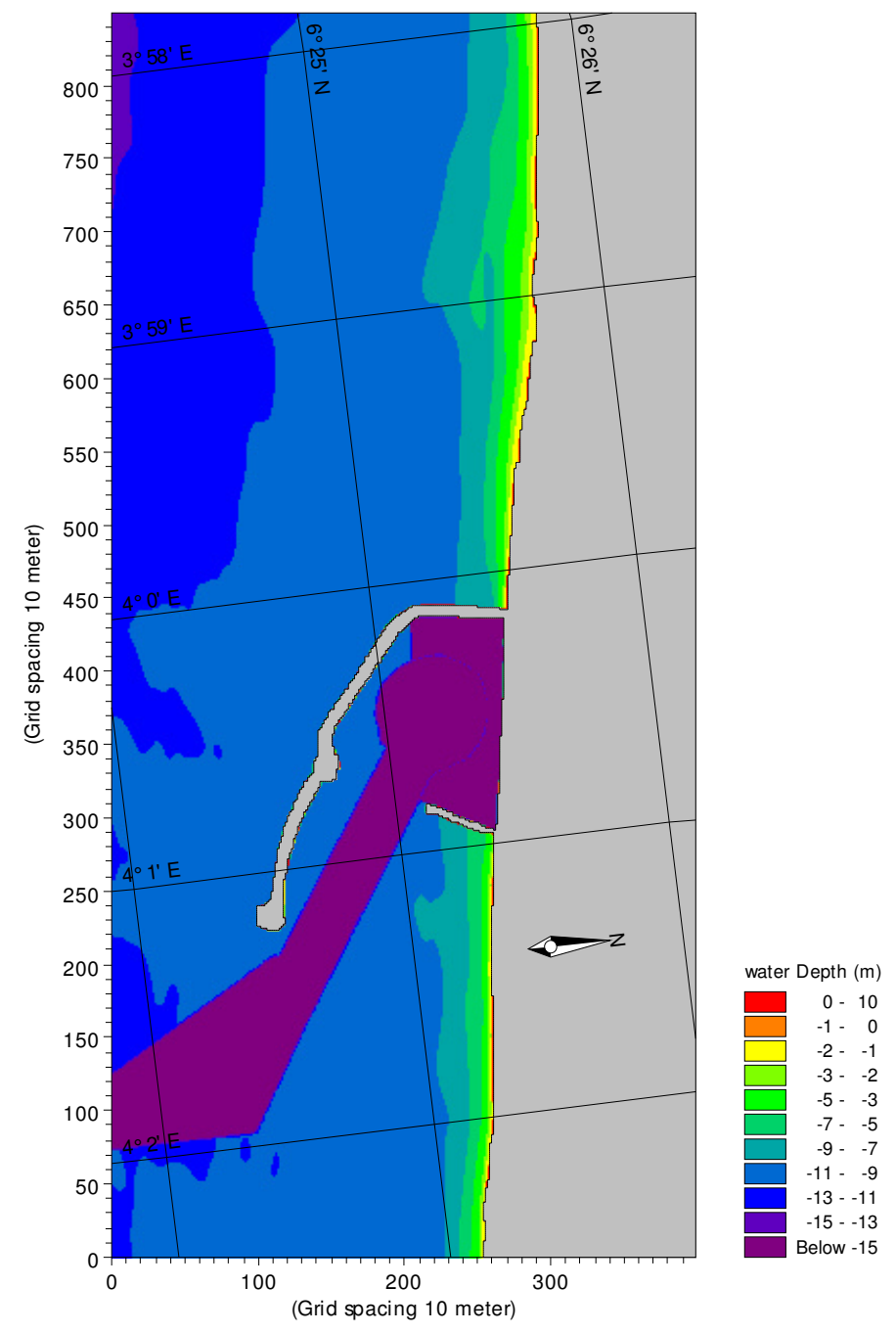

Figure $1 b$ Fine grid bathymetry

A regional bathymetry on a coarse grid covering an area of $70 \mathrm{~km} \times 17.5 \mathrm{~km}$ with a $250 \mathrm{~m} \times 250 \mathrm{~m}$ grid spacing is prepared using the water depth information available in the British Admiralty Chart 1863 (Fig. Ia). The model area extends from Lagos in the west to the study location at Lekki in the east. Again a local bathymetry covering a 9 $\mathrm{km} \times 11 \mathrm{~km}$ area with a finer grid spacing of $10 \mathrm{~m} \times 10 \mathrm{~m}$, is prepared using the water depth data obtained from field surveys (Fig.1b). The harbour facilities like the harbour breakwaters, navigational channel and seawater intake inside the port and outfall adjacent to eastern breakwater are digitally laid on the bathymetry. The tidal forcing at the eastern and western boundaries of the coarse grid model is used to drive the circulation within the fine grid model. The surface elevations at the eastern boundary (Lekki) and the western boundary (Lagos), are taken from tidal measurements observed for a period of 18 days. The same has formed as the boundary conditions for the HD 
simulations in the coarse grid. The observed tides at Lekki and Lagos are presented in Fig. $2 a \& 2 b$, which shows that the tidal range at Lekki during spring tide is close to $2.5 \mathrm{~m}$ while that during neap tide is 1.2 .

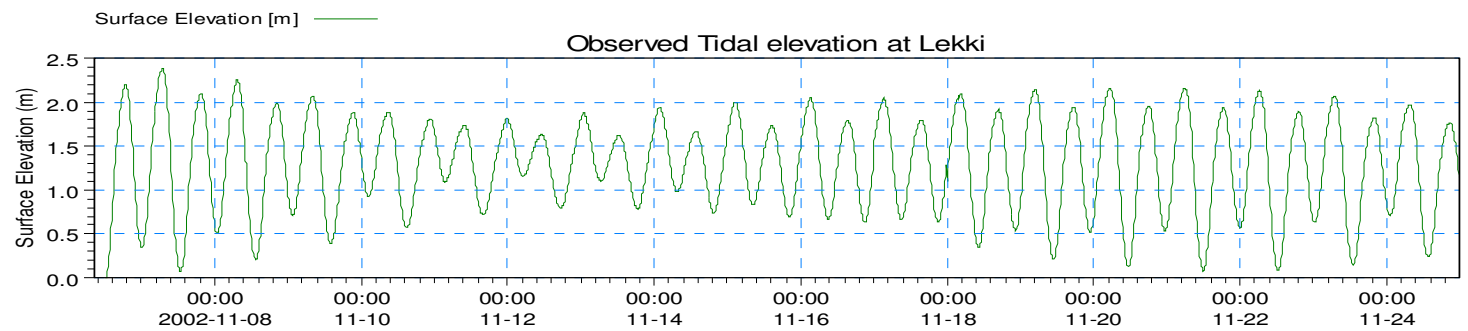

Figure 2a Observed tide at Lekki

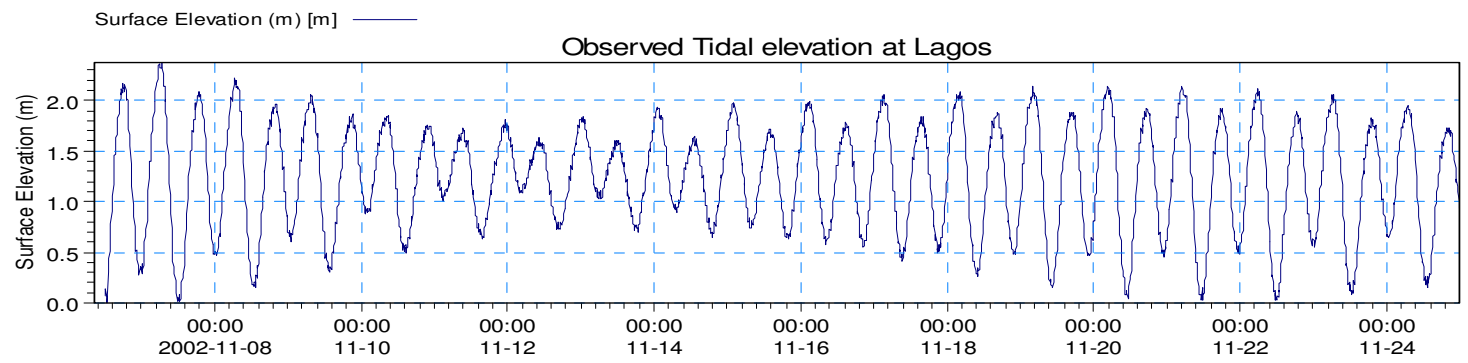

Figure $2 \boldsymbol{b}$ Observed tide at Lagos

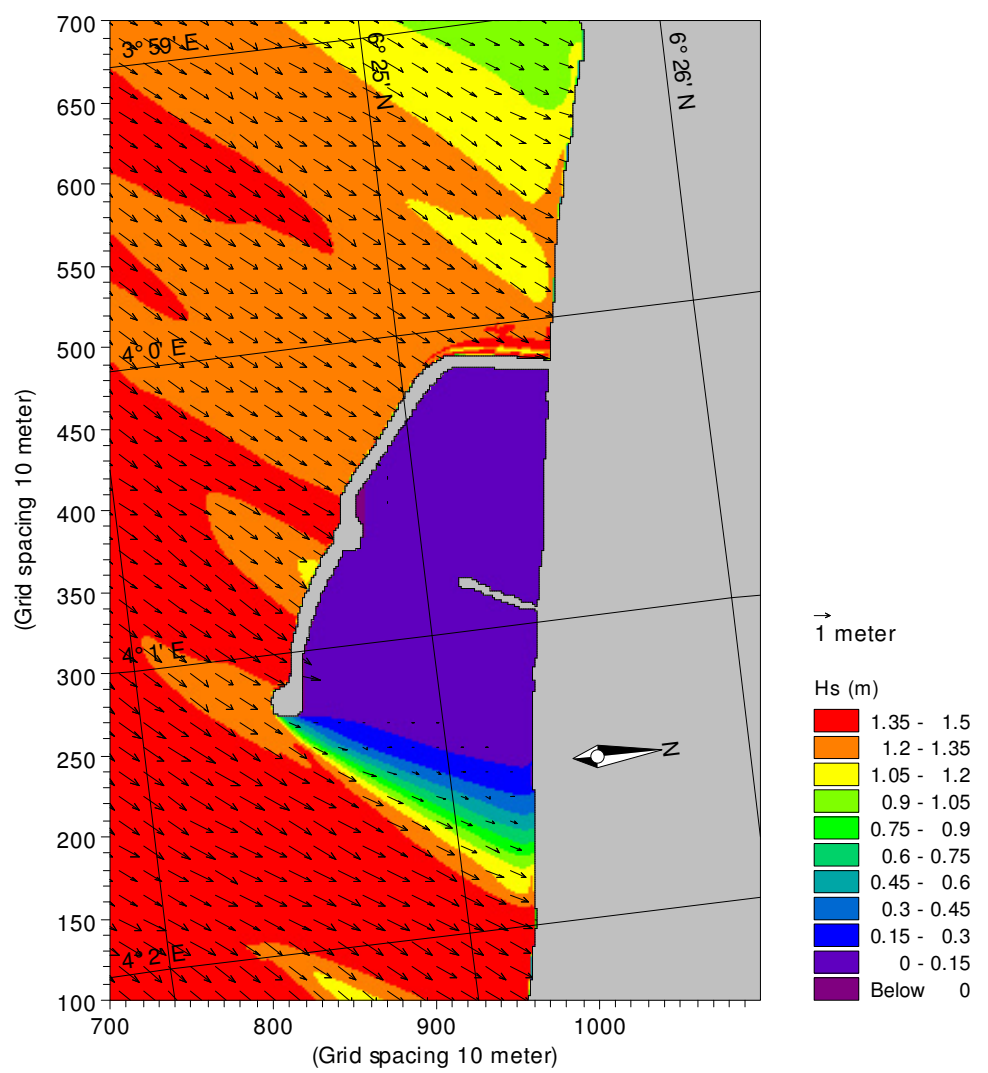

Figure 2c Simulated waves for the coastal stretch of study area

APPLIED ECOLOGY AND ENVIRONMENTAL RESEARCH 9(4): 341-354. http://www.ecology.uni-corvinus.hu • ISSN 15891623 (Print) • ISSN 17850037 (Online) (c) 2011, ALÖKI Kft., Budapest, Hungary 
Apart, wave plays a major role in shallow water hydrodynamics since wave induced radiation stress in the bulk of water contributes significantly to currents. The wave climate experienced at the study area is predominantly governed by the deep-water waves from south. Waves at shallow water generate radiation stress, which is responsible for mass transport. Hence wave induced radiation stress is modeled for creating input to combined wave-tide induced flow simulation. The near shore waves for the coast is simulated using parabolic mild slope wave model (boundary $\mathrm{Hs}=1.5 \mathrm{~m}$, $\mathrm{Tm}=5.2 \mathrm{~s}$ ) and the wave field is shown in the Fig. $2 c$. Two sets of model executions are performed spring and neap tide with waves.

\section{Model formulation}

The MIKE 21 Flow model (HD) simulates two-dimensional free-surface flows (Abbott et al., 1981). It calculates non-steady flow and transport phenomena that result from tidal and meteorological forcing on a spherical, or rectilinear or curvilinear boundary fitted grid. This model is applicable for the simulation of flow fields in natural water bodies, such as lakes, estuaries, bays, coastal areas and seas wherever stratification can be neglected. It can be used to model the processes like: tide and winddriven flows, stratified and density driven flows, hermal stratification in lakes, seas and reservoirs, cooling water re-circulation, transport of dissolved material and pollutants and wave-driven currents etc.

It is a multi-dimensional 2D, hydrodynamic flow simulation model, which solves shallow-water equations for given boundary conditions to compute non-steady flow fields in response to a variety of environmental forcing and processes in natural water bodies. The environmental forcing and processes include: bottom shear stress, wind shear stress, barometric pressure gradients, Coriolis force, momentum dispersion, sources and sinks, evaporation, flooding and drying and wave radiation stresses.

This model uses an Alternate Direction Implicit (ADI) Finite Difference Method on staggered orthogonal grids and also has the option to use Finite Element Method (Abbott, 1979). The basic shallow-water equations in the Cartesian co-ordinate system used in the HD flow modules are:

Continuity equation (1):

$$
\frac{\partial \zeta}{\partial \mathrm{t}}+\frac{\partial \mathrm{p}}{\partial \mathrm{X}}+\frac{\partial \mathrm{q}}{\partial \mathrm{Y}}=\mathrm{S}-\mathrm{e}
$$

Momentum equations in $\mathrm{x}$ - and $\mathrm{y}$ - directions ( $2 \& 3)$ :

$$
\begin{aligned}
& \frac{\partial \mathrm{p}}{\partial \mathrm{t}}+\frac{\partial}{\partial \mathrm{X}}\left[\frac{\mathrm{p}^{2}}{\mathrm{~h}}\right]+\frac{\partial}{\partial \mathrm{Y}}\left[\frac{\mathrm{p} \cdot \mathrm{q}}{\mathrm{h}}\right]+\mathrm{gh} \frac{\partial \zeta}{\partial \mathrm{X}}+\mathrm{F}_{\mathrm{bx}}-\mathrm{K}_{\mathrm{a}} \mathrm{WW}_{\mathrm{X}}-\frac{\mathrm{h}}{\rho_{\mathrm{W}}} \cdot \frac{\partial \mathrm{p}_{\mathrm{a}}}{\partial \mathrm{X}}-\Omega \mathrm{q}-\mathrm{F}_{\mathrm{EX}}=\mathrm{S}_{\mathrm{iX}} \text { (Eq.2) } \\
& \frac{\partial \mathrm{q}}{\partial \mathrm{t}}+\frac{\partial}{\partial \mathrm{X}}\left[\frac{\mathrm{p} \cdot \mathrm{q}}{\mathrm{h}}\right]+\frac{\partial}{\partial \mathrm{Y}}\left[\frac{\mathrm{q}^{2}}{\mathrm{~h}}\right]+\mathrm{gh} \frac{\partial \zeta}{\partial \mathrm{Y}}+\mathrm{F}_{\mathrm{by}}-\mathrm{K}_{\mathrm{a}} \mathrm{WW}_{\mathrm{Y}}-\frac{\mathrm{h}}{\rho_{\mathrm{W}}} \cdot \frac{\partial \mathrm{p}_{\mathrm{a}}}{\partial \mathrm{Y}}+\Omega \mathrm{p}-\mathrm{F}_{\mathrm{EY}}=\mathrm{S}_{\mathrm{iY}} \text { (Eq.3) }
\end{aligned}
$$

Where: 


$$
\begin{aligned}
& \mathrm{F}_{\mathrm{EX}}=\left[\frac{\partial}{\partial \mathrm{X}}\left[\varepsilon_{\mathrm{X}} \cdot \mathrm{h} \cdot \frac{\partial \mathrm{u}}{\partial \mathrm{X}}\right]+\frac{\partial}{\partial \mathrm{Y}}\left[\varepsilon_{\mathrm{Y}} \cdot \mathrm{h} \cdot \frac{\partial \mathrm{u}}{\partial \mathrm{Y}}\right]\right] \\
& \mathrm{F}_{\mathrm{EY}}=\left[\frac{\partial}{\partial \mathrm{X}}\left[\varepsilon_{\mathrm{X}} \cdot \mathrm{h} \cdot \frac{\partial \mathrm{u}}{\partial \mathrm{X}}\right]+\frac{\partial}{\partial \mathrm{Y}}\left[\varepsilon_{\mathrm{Y}} \cdot \mathrm{h} \cdot \frac{\partial \mathrm{u}}{\partial \mathrm{Y}}\right]\right] \\
& F_{b x}=\frac{\mathrm{g}}{\mathrm{C}^{2}} \sqrt{\frac{\mathrm{p}^{2}}{\mathrm{~h}^{2}}+\frac{\mathrm{q}^{2}}{\mathrm{~h}^{2}}} \cdot \frac{\mathrm{p}}{\mathrm{h}} \\
& F_{b y}=\frac{\mathrm{g}}{\mathrm{C}^{2}} \sqrt{\frac{\mathrm{p}^{2}}{\mathrm{~h}^{2}}+\frac{\mathrm{q}^{2}}{\mathrm{~h}^{2}}} \cdot \frac{\mathrm{q}}{\mathrm{h}}
\end{aligned}
$$

Where the following symbols are as:

$$
\begin{array}{ll}
\zeta(\mathrm{x}, \mathrm{y}, \mathrm{t}) & \text { Water surface level above datum }(\mathrm{m}) \\
\mathrm{p}(\mathrm{x}, \mathrm{y}, \mathrm{t}) & \text { flux density in the x-direction }\left(\mathrm{m}^{3} / \mathrm{s} / \mathrm{m}\right) \\
\mathrm{q}(\mathrm{x}, \mathrm{y}, \mathrm{t}) & \text { flux density in the y-direction }\left(\mathrm{m}^{3} / \mathrm{s} / \mathrm{m}\right) \\
\mathrm{h}(\mathrm{x}, \mathrm{y}, \mathrm{t}) & \text { water depth }(\mathrm{m}) \\
\mathrm{S} & \text { source magnitude per unit horizontal area }\left(\mathrm{m}^{3} / \mathrm{s} / \mathrm{m}^{2}\right) \\
\mathrm{S}_{\mathrm{iX}}, \mathrm{S}_{\mathrm{iY}} & \text { source impulse in } \mathrm{x} \text { and y-directions }\left(\mathrm{m}^{3} / \mathrm{s}^{2} / \mathrm{m}^{2} \cdot \mathrm{m} / \mathrm{s}\right) \\
\mathrm{e} & \text { evaporation rate }(\mathrm{m} / \mathrm{s}) \\
\mathrm{g} & \text { gravitational acceleration }\left(\mathrm{m} / \mathrm{s}^{2}\right) \\
\mathrm{C} & \text { Chezy resistance No. }\left(\mathrm{m}^{1 / 2} / \mathrm{s}\right) \\
\mathrm{K}_{\mathrm{a}} & \mathrm{C}_{\mathrm{w}} \frac{\rho_{\text {air }}}{\rho_{\text {Water }}} \\
\mathrm{C}_{\mathrm{w}} & \text { wind friction factor } \\
\mathrm{W}, \mathrm{W}_{\mathrm{X}}, \mathrm{W}_{\mathrm{Y}}(\mathrm{x}, \mathrm{y}, \mathrm{t}) & \text { wind speed and components in } \mathrm{x}-\text { and } \mathrm{y}-\mathrm{directions}(\mathrm{m} / \mathrm{s}) \\
\mathrm{p}_{\mathrm{a}}(\mathrm{x}, \mathrm{y}, \mathrm{t}) & \text { barometric pressure }\left(\mathrm{Kg} / \mathrm{m} / \mathrm{s}^{2}\right) \\
\rho_{\mathrm{w}} & \text { density of water }\left(\mathrm{kg} / \mathrm{m}^{3}\right) \\
\Omega & \text { Coriolis coefficient }(\text { latitude dependent })\left(\mathrm{s}^{-1}\right) \\
\varepsilon(\mathrm{x}, \mathrm{y}) & \text { eddy or momentum dispersion coefficient }\left(\mathrm{m}^{2} / \mathrm{s}\right) \\
\mathrm{x}, \mathrm{y} & \text { space coordinates }(\mathrm{m}) \\
\mathrm{t} & \text { time (s) }
\end{array}
$$

In this study the intake volume of $400,000 \mathrm{~m}^{3} / \mathrm{hr}$ is included in the model as several isolated sinks, while the reject water at the outfall location is included in the model as isolated sources. These sources / sinks discharge / remove the above volume of seawater 
throughout the simulation period. A heat dissipating component with a temperature difference of $+10{ }^{\circ} \mathrm{C}$ above the ambient seawater temperature is specified at the individual sources in the outfall location, to study the movement of the reject water plume in space and time. The simulations are carried out for duration of $60 \mathrm{hrs}$ in each case, out of which the model is allowed to warm up (stabilize) for the initial 12 hours and the results for the subsequent 48 hours only are used for further analysis. The result of these simulations is formed the hydrodynamic basis for the subsequent advectiondispersion modeling to study the movement of the reject water.

The advection-dispersion model (AD) of the MIKE 21 system simulates the spreading of effluent in an aquatic environment under the influence of the fluid transport and associated natural dispersion process (Gross et al., 2002). The substance may be a pollutant of any kind, conservative or non-conservative, inorganic or organic: e.g. salt, heat, dissolved oxygen, inorganic phosphorus, nitrogen and other such water quality parameters.

The temperature/concentration of the substance is calculated at each point of a rectangular grid covering the area of interest, in a way similar to the hydrodynamic computations. This module determines the concentration of the substance by solving the equation of conservation of heat/mass for a dissolved or suspended substance using a two-dimensional form of the finite difference scheme (Ekebjaerg and Justesen, 1991). The MIKE $21 \mathrm{HD}$ model provides information on the transport, i.e. currents and water depths at each point of the grid. Other data required includes substance temperature/concentration and discharge quantities at outfalls, together with temperature/concentrations at boundaries.

The AD module solves the advection-dispersion equation for dissolved or suspended substances in two dimensions (Gross et al., 1998). This is in reality the mass/heat conservation equation to which quantities of substances discharged and their concentrations/temperature at source and sink points are included together with their decay rate (Vieira, 1992). The layer integrated advective transport equation for a substance $c$ was stated in Eq.l, and including source/sink terms it reads:

$$
\begin{gathered}
\frac{\partial \mathrm{hc}}{\partial \mathrm{t}}+\nabla \cdot(\overline{\mathrm{ufc}})+(\mathrm{wc})^{+}-(\mathrm{wc})^{-}=\mathrm{S}_{\mathrm{AD}} \\
\mathrm{S}_{\mathrm{AD}}=\mathrm{Pc}_{\mathrm{P}}-\mathrm{Ec}_{\mathrm{E}}+\frac{\mathrm{Q}_{\mathrm{H}}}{\rho \mathrm{C}_{\mathrm{HW}}}+\sum_{\mathrm{i}_{\mathrm{S}}=1}^{\mathrm{N}_{\mathrm{S}}} \delta\left(\overline{\mathrm{X}}-\overline{\mathrm{X}}_{\mathrm{S}, \mathrm{i}_{\mathrm{s}}}\right) \mathrm{c}_{\mathrm{S}, \mathrm{i}_{\mathrm{S}}} \mathrm{Q}_{\mathrm{S}, \mathrm{i}_{\mathrm{S}}}+\sum_{\mathrm{i}_{\mathrm{D}}=1}^{\mathrm{N}_{\mathrm{D}}} \delta\left(\overline{\mathrm{X}}-\overline{\mathrm{X}}_{\mathrm{D}, \mathrm{i}_{\mathrm{D}}}\right) \mathrm{D}_{\mathrm{i}_{\mathrm{D}}}
\end{gathered}
$$

Where the following symbols are as:

$\begin{array}{ll}\mathrm{c} & \text { Temperature } \\ \delta & \text { delta function of horizontal coordinates, } \mathrm{m}^{-2} \\ \bar{X}_{S, i_{S}} & \text { horizontal coordinate of point source/sink No. } i_{s} \\ c_{S, i_{S}} & \text { Temperature of point source/sink No. } i_{s},[\mathrm{c}] \\ Q_{S, i_{S}} & \text { discharge at point source/sink No. . } i_{s} \\ P & \text { precipitation rate at surface }\end{array}$




$\begin{array}{ll}c_{p} & \text { air temperature } \\ \mathrm{E} & \text { evaporation rate at surface } \\ c_{E} & \text { temperature of the ambient water } \\ Q_{H} & \text { heat flux from heat exchange module (if c is temperature), W/ } \mathrm{m}^{2} \\ \rho & \text { density of water, } \mathrm{kg} / \mathrm{m}^{3} \\ C_{H W} & \text { specific heat of water, } 4186 \mathrm{~J}\left(\mathrm{~kg}^{\mathrm{o}} \mathrm{K}\right) \\ D_{i_{D}} & \text { dry deposition rate, [c] } \\ \bar{X}_{D, i_{D}} & \text { horizontal coordinate of dry contributor No. } i_{D}\end{array}$

\section{Results}

The combined wave-tide induced flow hydrodynamics for the study area is simulated and results are presented in this section. The flow pattern during spring tide, with waves resulted the strongest currents along the western breakwater, during flood (inflow) and ebb (outflow) phases of the tide shown in Fig. $3 a$ and $4 a$ respectively.

The flow pattern during ebb is slightly altered at outfall location and the reject water flows eastwards close to the western breakwater, while the general flow is directed westwards. The speed of the eastward flowing current along the western breakwater are higher during flood phase, due to the combined action of waves, tidal flow and reject water outfall. Current speeds approaching $0.5 \mathrm{~m} / \mathrm{s}$ are simulated along the western breakwater during flood phase, while the regions of the entrance channel behind the western breakwater and the harbour basin are generally calm. The currents are altered at the tip of western breakwater resulting in different flow patterns, depending on the direction of flow during the tidal cycle.

The corresponding reject water plume movement during flood and ebb are shown in Fig. $3 b$ and $4 b$ respectively. The combined effects of the waves and tides tend to dilute the temperature of the reject water plume, thus resulting a temperature differences at intake location during flood and ebb phases is less then $0.5{ }^{\circ} \mathrm{C}$.The maximum temperature difference is observed at the harbour entrance $0.8{ }^{\circ} \mathrm{C}$. It shows that the maximum increase in temperature over the ambient seawater, is close to $2.0^{\circ} \mathrm{C}$ at the harbour, though this decreases to a maximum of $0.5^{\circ} \mathrm{C}$ at the intake location.

Similarly, current vectors depicting the flow pattern during neap tide along with waves are presented in Fig. $5 a$ and $6 a$. The eastward flowing currents along the western breakwater is present in both phases, the current speeds being higher during flood than the ebb phase. This shows that the weak tidal currents do not seem to influence the direction of movement of the reject water, irrespective of the flood or the ebb phase of the tide. The reject water plumes for neap tides with waves are presented in Fig. $5 b$ and $6 b$. It is seen that the plume movement is similar to that during spring tide. There are exception with the increase in temperature over the ambient waters and slightly higher during neap tide, due to the weaker tidal currents. 


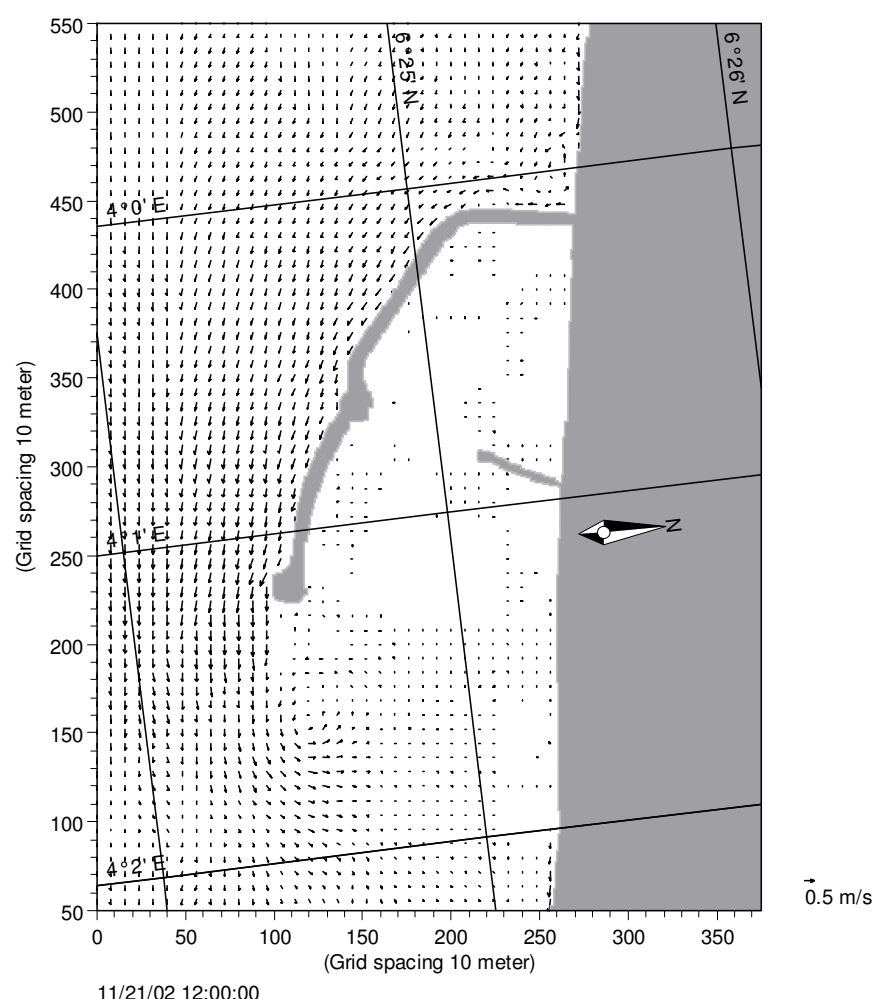

Figure 3a Hydrodynamic flow pattern for spring tide (flood) with waves

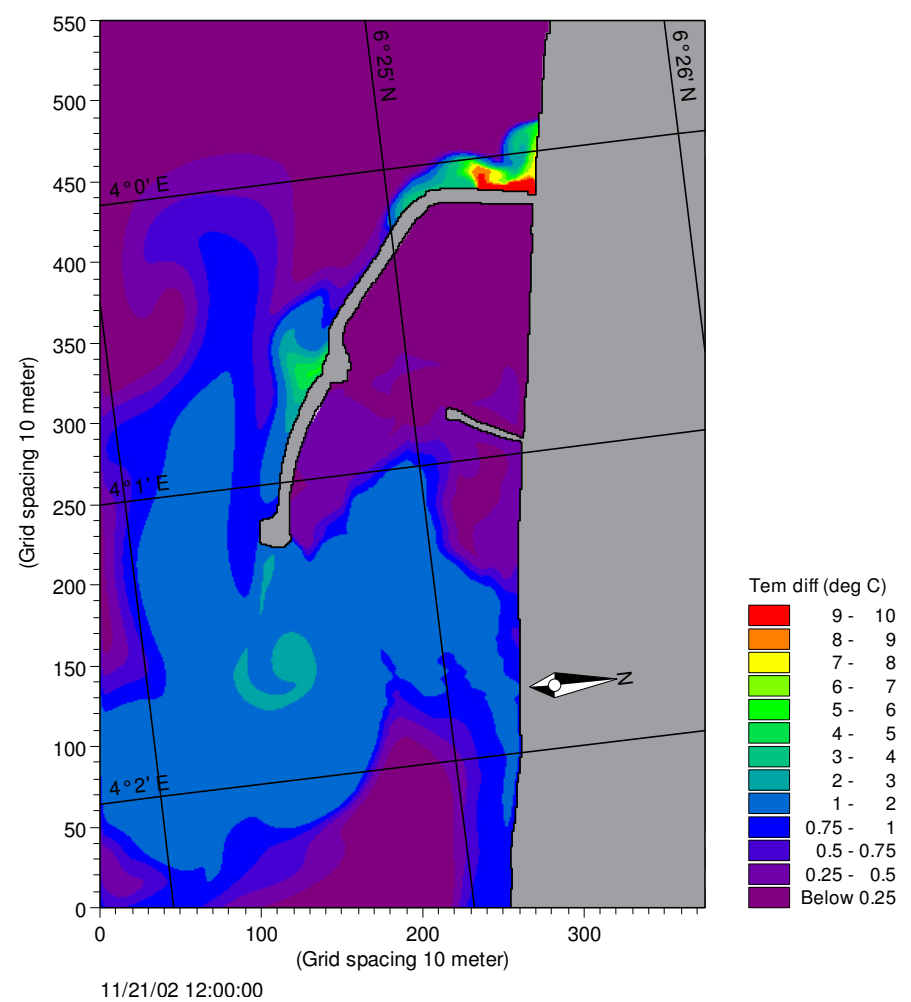

Figure $3 \boldsymbol{b}$ Advection dispersion corresponding to 3(a) 


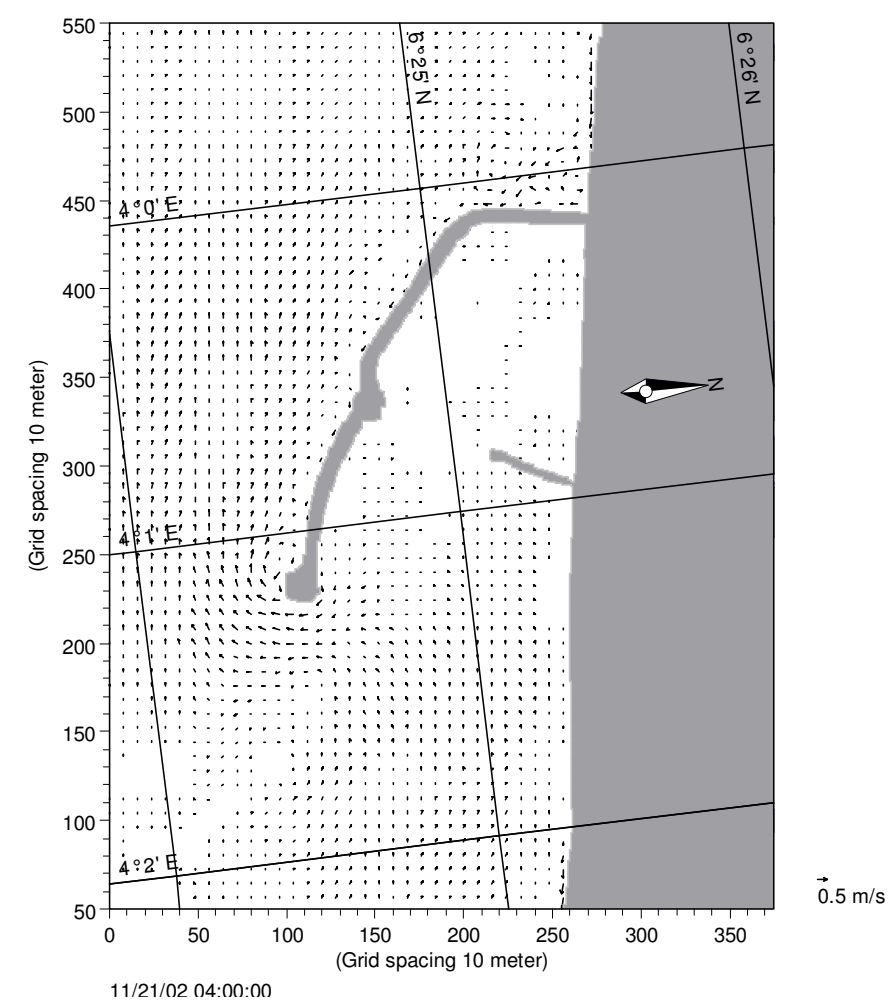

Figure 4a Hydrodynamic flow pattern for spring tide (ebb) with waves

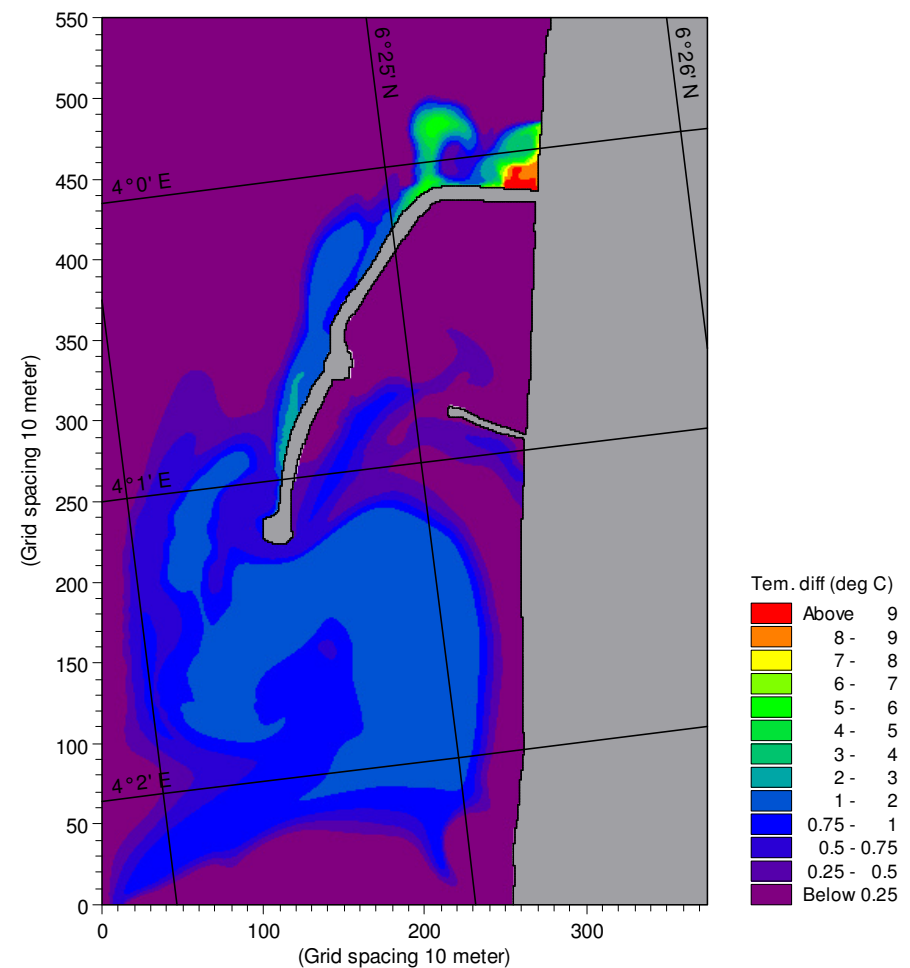

11/21/02 04:00:00

Figure $4 \boldsymbol{b}$ Advection dispersion corresponding to $4(a)$

APPLIED ECOLOGY AND ENVIRONMENTAL RESEARCH 9(4): 341-354. http://www.ecology.uni-corvinus.hu • ISSN 15891623 (Print) • ISSN 17850037 (Online) (c) 2011, ALÖKI Kft., Budapest, Hungary 


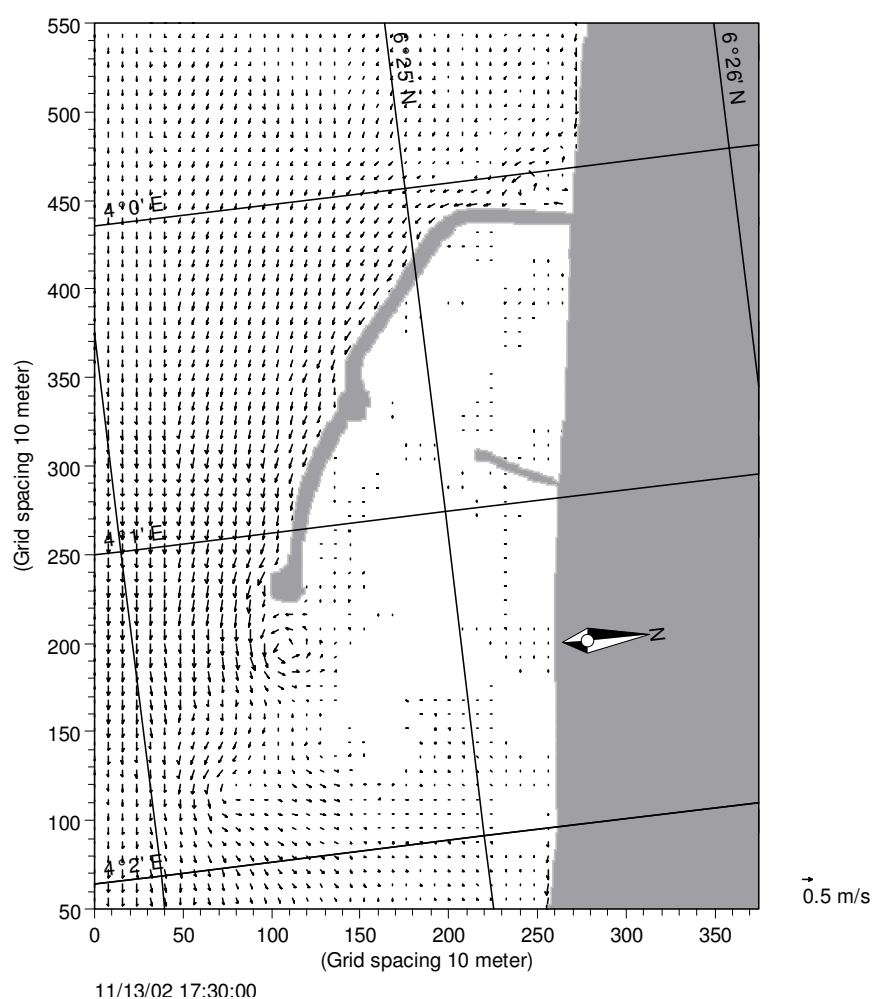

Figure 5a Hydrodynamic flow pattern for neap tide (flood) with waves

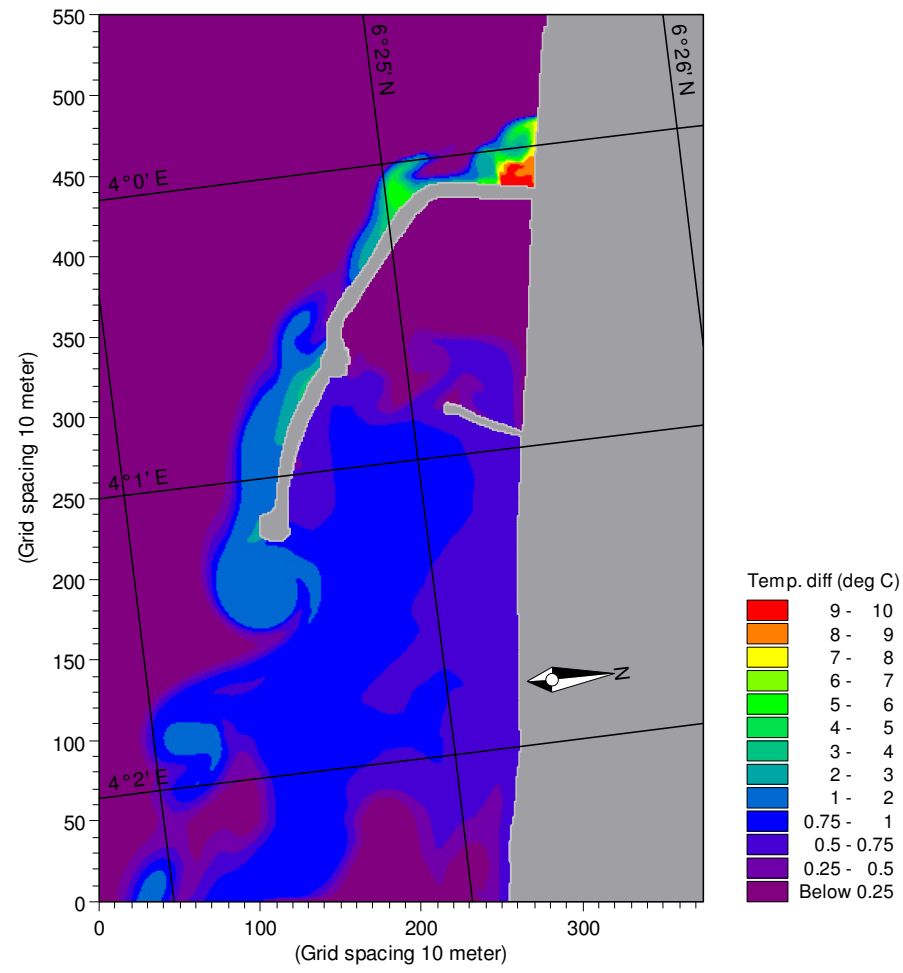

Figure $\mathbf{5 b}$ Advection dispersion corresponding to 5(a)

APPLIED ECOLOGY AND ENVIRONMENTAL RESEARCH 9(4): 341-354. http://www.ecology.uni-corvinus.hu • ISSN 15891623 (Print) • ISSN 17850037 (Online) (c) 2011, ALÖKI Kft., Budapest, Hungary 


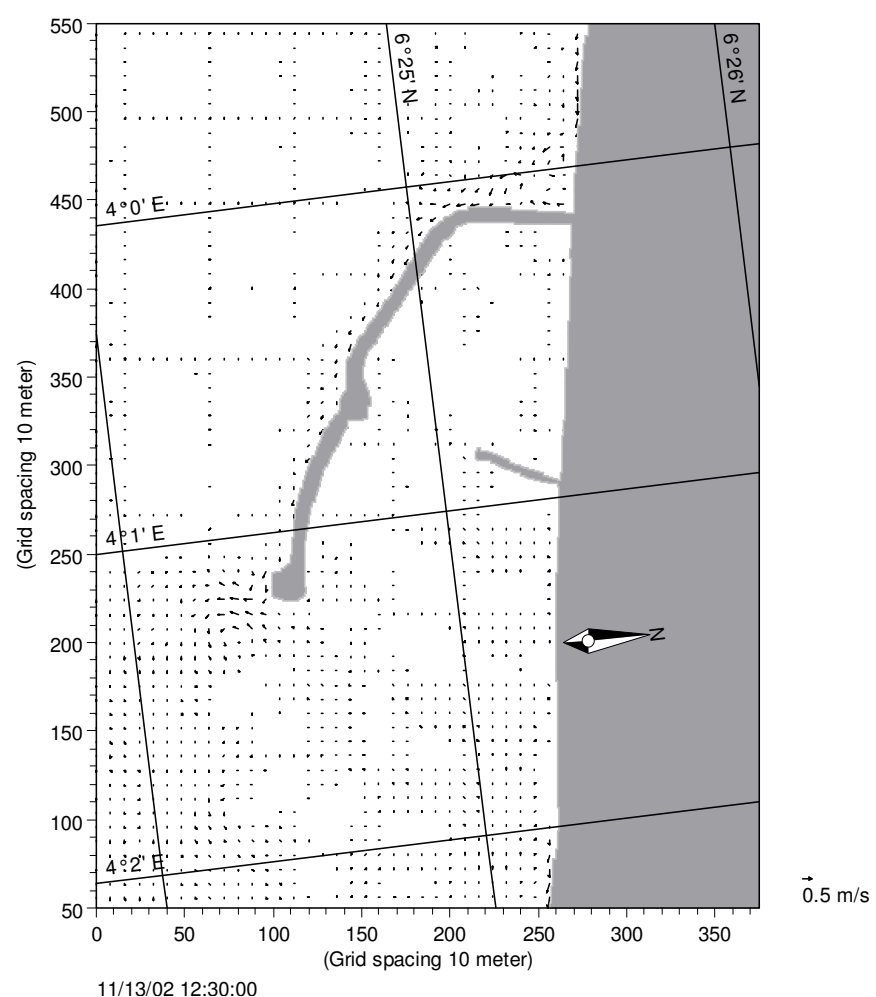

Figure 6a Hydrodynamic flow pattern for neap tide (ebb) with waves

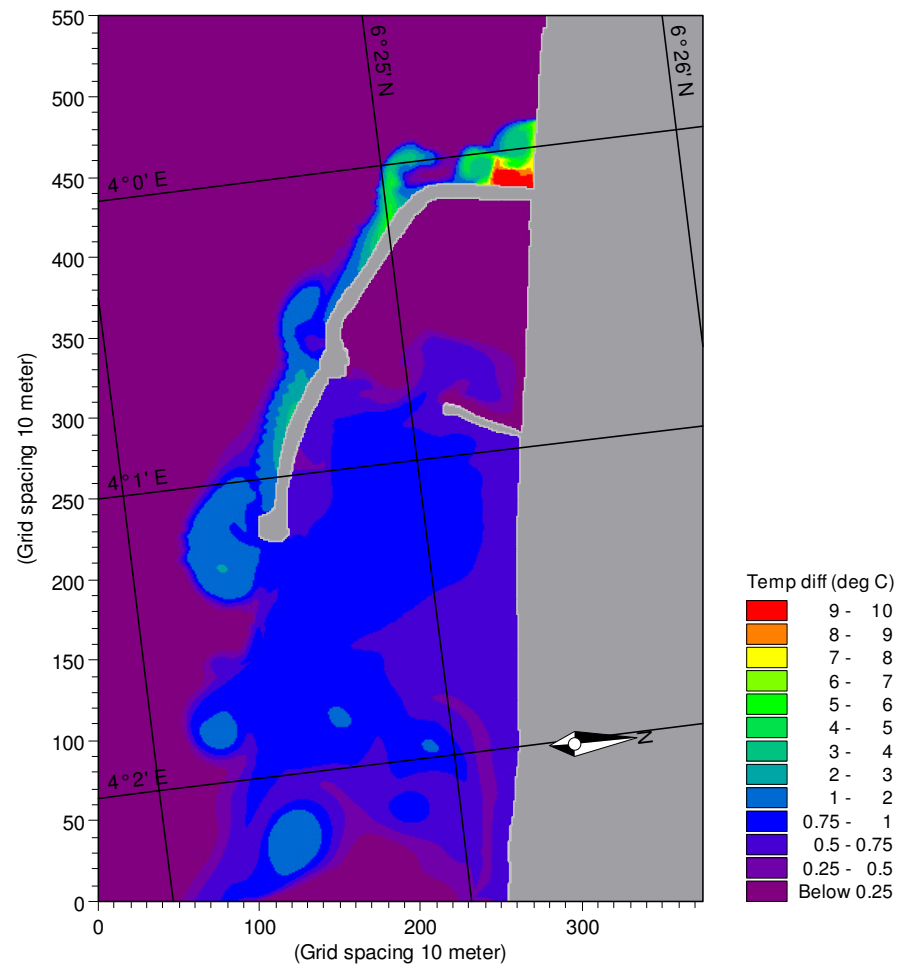

Figure $\mathbf{6 b}$ Advection dispersion corresponding to 6(a) 


\section{Discussions and conclusion}

The results of the Advection- Dispersion simulations show that the reject water moves eastwards along the western breakwater during spring tide for both the flood phase and ebb phase of the tide. The extent of the plume movement and temperature increase over the ambient waters is higher during the flood phase than that during ebb. The combined effect of the waves and tidal currents during spring tide increases the plume dilution, thus resulting in smaller temperature differences. The reject water plumes for neap tides with waves show that the temperature increase over the ambient waters is higher due to the weaker tidal currents. The Advection Dispersion simulations for combined tide and waves show that there is no effect of the reject water on the temperature of the seawater at the intake location. Also the dilution is increasing with distance from the discharge point. The flow pattern in the coastal waters ensures sufficient dilution of the reject and the maximum temperature increase of the ambient seawater is close to $2{ }^{\circ} \mathrm{C}$ at the entrance to the harbour, while this value decreases to $0.5^{\circ} \mathrm{C}$ at the intake location. The plume dispersion doesn't significantly influence the environment as the maximum rise in temperature is $<2{ }^{\circ} \mathrm{C}$, which is well within the environmental guidelines. The immediate coastal environment at disposal location has a temperature difference in the order of $5-10{ }^{\circ} \mathrm{C}$ for an area of $200 \times 300 \mathrm{~m}$. This study shows that numerical models play an important role in this regard, as steady state analytical calculations fail to address the temporal and spatial change in these parameters. The model is an useful tool to select disposal location but it needs calibration to make more meaningful. It fairly monitors the heated water spreading and a good decision support system for environmental impact assessment.

Acknowledgements. The authors are thankful to L\&T-Ramboll for the encouragement and support during this work.

\section{REFERENCES}

[1] Abbott, M.B. (1985): Modeling circulation's in depth-integrated flows. Part-1: The accumulation of the evidence. - Journal of Hydraulic Research 23(4).

[2] Abbott, M.B. (1979): Computational Hydraulics - Elements of the Theory of Free Surface Flows. - Pitman, London.

[3] Abbott, M.B., Mc Cowan, Warren, I.R. (1981): Numerical Modeling of Free-Surface Flows that are two-dimensional in Plan. - Proceedings of a symposium on predictive ability of transport models for Inland and Coastal waters, Academic Press.

[4] Ekebjaerg, L., Justesen, P. (1991): An explicit Scheme for Advection Diffusion Modeling in two dimensions. - Compute Methods in Applied Mechanics and Engineering 88(3): 287-297.

[5] Gross, E.S., Bonaventura, L., Rosatti, G. (2002): Consistency with Continuity in Conservative Advective Schemes for Free Surface Models. - International Journal for Numerical Methods in Fluids 38: 307-327.

[6] Gross, E.S., Casulli, V., Bonaventura, L., Koseff, J.R. (1998): A semi-Implicit Method for Vertical Transport in Multidimensional Models. - International Journal for Numerical Methods in Fluids 28: 157-186.

[7] Rodi, W. (1980): Turbulence Models and their applications in Hydraulics. A State of the Art Review. - SFB 80/T/127. 
[8] Vieira, J.R. (1992): On the general dispersive coefficients used in mathematical models of flow circulation and transport. - Coastal, Estuarial and Harbour Engineer's Reference Book.

[9] Wood, I.R., Bell, R.G., Wilkinson, D.L. (1993): Ocean disposal of wastewater. Advanced series on Ocean Engineering, vol. 8, World Scientific, Singapore. 